\title{
Lipomobilization in periparturient dairy cows influences the composition of plasma nonesterified fatty acids and leukocyte phospholipid fatty acids
}

\author{
G. A. Contreras, N. J. O’Boyle, T. H. Herdt, and L. M. Sordillo' \\ Department of Large Animal Clinical Sciences, Michigan State University, East Lansing 48824
}

\section{ABSTRACT}

The periparturient period is characterized by sudden changes in metabolic and immune cell functions that predispose dairy cows to increased incidence of disease. Metabolic changes include alterations in the energy balance that lead to increased lipomobilization with consequent elevation of plasma nonesterified fatty acids (NEFA) concentrations. The objective of this study was to establish the influence of lipomobilization on fatty acid profiles within plasma lipid fractions and leukocyte phospholipid composition. Blood samples from 10 dairy cows were collected at 14 and $7 \mathrm{~d}$ before due date, at calving, and at 7, 14, and $30 \mathrm{~d}$ after calving. Total lipids and lipid fractions were extracted from plasma and peripheral blood mononuclear cells. The degree of lipomobilization was characterized by measurement of plasma NEFA concentrations. The fatty acid profile of plasma NEFA, plasma phospholipids, and leukocyte phospholipids differed from the composition of total lipids in plasma, where linoleic acid was the most common fatty acid. Around parturition and during early lactation, the proportion of palmitic acid significantly increased in the plasma NEFA and phospholipid fractions with a concomitant increase in the phospholipid fatty acid profile of leukocytes. In contrast, the phospholipid fraction of long-chain polyunsaturated fatty acids in leukocytes was diminished during the periparturient period, especially during the first 2 wk following parturition. This study showed that the composition of total plasma lipids does not necessarily reflect the NEFA and phospholipid fractions in periparturient dairy cows. These findings are significant because it is the plasma phospholipid fraction that contributes to fatty acid composition of membrane phospholipids. Increased availability of certain saturated fatty acids in the NEFA phospholipid fractions may contribute to altered leukocyte functions during the periparturient period.

Received November 2, 2009.

Accepted March 1, 2010.

${ }^{1}$ Corresponding author: Sordillo@msu.edu
Key words: nonesterified fatty acids, peripheral blood mononuclear cells, periparturient, lipomobilization

\section{INTRODUCTION}

The onset of lactation imposes vast energy demands on the dairy cow, involving considerable changes in both dietary requirements and metabolic functions. In dairy cows, the energy requirements of early lactation are generally not met by the diet, and mobilization of tissue energy reserves is required. Mobilization of lipids from tissue stores involves the release of fatty acids into the blood stream. Fatty acids are transported in circulation by various lipid fractions that include neutral lipids (NL), phospholipids (PL), and NEFA. The NL fraction is composed of triglycerides, diglycerides, monoglycerides, and cholesteryl esters. Both NL and PL are carried by lipoproteins including very low density lipoprotein, low density lipoprotein, and high density lipoprotein that function to maintain the lipids in aqueous solution. Fatty acids from these molecules are made available to cell metabolism by the action of lipoprotein lipases (Tall, 1995). In contrast, NEFA are held in solution in combination with albumin, although a small portion of NEFA is transported as unbound monomers in aqueous solution (Richieri and Kleinfeld, 1995). Circulating NEFA are readily available for complete oxidation by a variety of tissues. However, a large portion of them is either partially oxidized to ketone bodies or re-esterified to form triglycerides in the liver (Grummer, 1993; Hocquette and Bauchart, 1999).

In humans, the fatty acid profiles of plasma lipid fractions and erythrocyte cellular membranes vary greatly during the last trimester of gestation through the first weeks of lactation (Al et al., 1995; Otto et al., 2001). These shifts are a consequence of elevated requirements for fatty acids by the growing fetus and mammary gland (Al et al., 1995; Otto et al., 2001; Hanebutt et al., 2008). Similarly, dairy cows experience a sharp increase in concentrations of lipids in plasma during the periparturient period in response to higher metabolic demands driven by fetal needs and the onset of lactation (Drackley, 1999). This characteristic was described quantitatively for the NEFA fraction. Plasma NEFA in 
late lactation and the dry period average less than 0.2 $\mathrm{m} M / \mathrm{L}$. Concentrations start to increase $2 \mathrm{wk}$ before parturition reaching the highest point during the first $10 \mathrm{~d}$ of lactation with concentrations of approximately $0.750 \mathrm{~m} M / \mathrm{L}$ depending on the degree of lipomobilization. Concentrations may surpass $1.0 \mathrm{mM} / \mathrm{L}$, especially in cows that are destined to develop ketosis (Adewuyi et al., 2005). These alterations in serum lipids have consequences not only for energy redistribution but also for cell metabolism and function.

Disturbances in adipose tissue function and lipid homeostasis (lipodystrophies and dyslipidemias) in human and animal models can lead to insulin resistance and metabolic disorders including altered cellular immune status (Montecucco and Mach, 2009). Fatty acids can affect cellular immune function by modifying intracellular signaling, associating with lipid-raft proteins, binding to specific toll-like receptors, controlling gene expression, activating transcription factors, inducing apoptosis, and modifying lipid mediator production (Calder and Yaqoob, 2007). Therefore, the fatty acid composition of immune cells directly affects their activity. The effect of specific fatty acids on immune cell function was described in humans (Håversen et al., 2009). However, changes in the fatty acid profile of the plasma NEFA and PL fractions during the periparturient period of dairy cows are not well defined in the literature. Furthermore, the implications of shifts in the fatty acid composition of bovine immune cell lipid fractions are largely unknown. The objective of this study was to describe the variations in the fatty acid profile of NEFA, plasma PL fractions, and PL content of peripheral blood mononuclear cells (PBMC) obtained from periparturient dairy cows.

\section{MATERIALS AND METHODS}

\section{Animals and Diets}

All animal procedures were approved by the Michigan State University Animal Care and Use Committee. Ten healthy, mature, multiparous Holstein cows were selected at the moment of dry-off from a large, commercial Michigan dairy herd. Animals were chosen based on the following criteria: $>210 \mathrm{~d}$ of gestation, a last DHI test with SCC $<250,000$ cells $/ \mathrm{mL}$, and a BCS of 3.5 to 3.75 . During the trial, cows were monitored for health status and exhibited no lameness or other disease. Animals were housed in freestalls and fed 2 different rations based on lactation status - a transition diet and a lactation diet. The ration composition and fatty acid profile of each diet is shown in Tables 1 and 2. Samples were collected when dry cows entered the close-up pen at $14 \mathrm{~d}$ before expected calving, $1 \mathrm{wk}$ later at $7 \mathrm{~d}$ before due date, at calving, and at 7, 14, and 30 d after calving.

\section{Isolation of PBMC}

Samples were collected in the morning between 0800 and $0900 \mathrm{~h}$ after feed was delivered. Blood $(150 \mathrm{~mL})$ was obtained by jugular venipuncture and immediately

Table 1. Ingredient composition (kg of DM, unless otherwise noted) of precalving and lactation diets

\begin{tabular}{|c|c|c|}
\hline \multirow[b]{2}{*}{ Item } & \multicolumn{2}{|c|}{ Diet } \\
\hline & Transition & Lactation \\
\hline \multicolumn{3}{|l|}{ Ingredient } \\
\hline Alfalfa haylage $^{1}$ & 0 & 6.52 \\
\hline Corn silage $^{2}$ & 14.27 & 23.53 \\
\hline Wheat straw & 4.24 & 0.46 \\
\hline Wet corn gluten & 1.23 & 1.14 \\
\hline Dry corn gluten & 0 & 1.28 \\
\hline Bakery by-product & 0 & 1.23 \\
\hline Canola meal & 0 & 1.00 \\
\hline Corn grain, medium grind & 0 & 1.78 \\
\hline Soybean meal, solvent & 0 & 2.01 \\
\hline Dried citrus pulp & 0 & 1.28 \\
\hline Wet beet pulp & 0 & 3.97 \\
\hline High moisture corn & 0 & 2.22 \\
\hline Supplements and mineral mix & 0.55 & 1.60 \\
\hline Vitamin ADE $\operatorname{mix}^{3}$ & 0.04 & 0.02 \\
\hline Trace mineral mix $^{4}$ & 0 & 0.02 \\
\hline Selenium blend ${ }^{5}$ & 0.05 & 0 \\
\hline Vitamin $\mathrm{E}^{6}$ & 0.005 & 0 \\
\hline Sodium selenate & 0.003 & 0 \\
\hline Sodium sesquicarbonate & 0 & 0.52 \\
\hline Calcium carbonate & 0.134 & 0.47 \\
\hline Sodium chloride & 0.078 & 0.26 \\
\hline Ground soybean hulls & 0.096 & 0 \\
\hline Wheat middlings & 0 & 1.2 \\
\hline Magnesium sulfate & 0.187 & 0 \\
\hline Calcium sulfate & 0.311 & 0 \\
\hline Magnesium oxide & 0.062 & 0.067 \\
\hline Blood meal & 0.187 & 0.552 \\
\hline Fishmeal & 0.062 & 0.247 \\
\hline Biotin 1\% & 0.005 & 0.004 \\
\hline Mepron $^{7}$ & 0 & 0.01 \\
\hline Tallow & 0.024 & 0.1 \\
\hline Rumensin $80^{8}$ & 0.004 & 0.003 \\
\hline \multicolumn{3}{|l|}{ Chemical analysis, $\%$ of DM } \\
\hline $\mathrm{NDF}$ & 50.9 & 29.2 \\
\hline $\mathrm{ADF}$ & 29.9 & 16.89 \\
\hline Ether extract & 3.08 & 3.9 \\
\hline $\mathrm{NE}_{\mathrm{L}}, \mathrm{MJ} / \mathrm{kg}$ of $\mathrm{DM}$ & 5.49 & 7.27 \\
\hline
\end{tabular}

${ }^{1}$ Alfalfa haylage $42 \% \mathrm{DM}$ (as fed).

${ }^{2}$ Corn silage $31 \%$ DM (as fed).

${ }^{3}$ Vitamin ADE mixture contained $(\mathrm{g} / \mathrm{kg}) 10.8$ retinyl acetate, 0.18 cholecalciferol, and $0.047 \mathrm{DL}-\alpha$-tocopherol.

${ }^{4}$ Trace mineral mix contained ( $\mathrm{g} / 100 \mathrm{~g}$ ): 13.0 calcium, 0.3 magnesium, 2.0 copper, 8.8 magnesium, 12.0 sulfur, 10.5 zinc, 0.3 manganese, 0.25 cobalt, and 0.19 iodine.

${ }^{5}$ Selenium blend contains $0.006 \%$ sodium selenite.

${ }^{6}$ Vitamin E contained $68.0 \mathrm{~g} / \mathrm{kg}$ of DL- $\alpha$-tocopherol.

${ }^{7}$ Rumen-protected methionine; Evonik Industries AG, Essen, Germany.

${ }^{8}$ Elanco Animal Health, Greenfield, IN. 
mixed with $15 \mathrm{~mL}$ of $40 \mathrm{~m} M$ EDTA solution containing ascorbic acid $(5 \mathrm{~g} / \mathrm{L})$. The PBMC were isolated by differential gradient using Ficoll-Paque Plus (GE Healthcare, Uppsala, Sweden), collected at the interface after centrifugation $(456 \times g$ for $30 \mathrm{~min})$, and washed 3 times with Hanks' balanced salt solution. The PBMC and plasma samples were stored at $-80^{\circ} \mathrm{C}$ until the lipid extraction procedure. A subsample of PBMC was collected to determine cellular populations using flow cytometry as described previously (Shafer-Weaver et al., 1999). Cells were incubated with each of the following lineage-specific bovine monoclonal antibodies (VMRD, Pullman, WA): CD2 (T lymphocytes BAQ95A at 1:100 vol/vol), CD3 (T-cell receptor MM1A at 1:100 vol/vol), CD4 (T-helper CACT83B at 1:160 vol/vol), B-B2 (B-lymphocytes BAQ44A at 1:150 vol/vol), MG (monocyte/granulocyte CD172a DH59B at 1:100 vol/ vol), and CD14 (monocyte M-M8 at 1:50 vol/vol).

\section{Lipid Extractions}

Total lipids from plasma and PBMC were extracted using a hexane:ethanol (1:1) solvent mix. Plasma or a saline solution containing at least $1 \times 10^{7}$ PBMC per $\mathrm{mL}$ were combined with the solvent mix and vortexed for $10 \mathrm{~min}$, and then centrifuged at 2,095 $\times \mathrm{g}$ for 10 min at room temperature. Finally, the top hexane layer was collected for total fatty acid composition and lipid fractioning. Nonadecanoic acid was used as internal standard.

Lipids were further separated into NL, NEFA, and PL fractions by solid-phase extraction using Strata cartridges containing aminopropyl $\left(\mathrm{NH}_{2}\right)$ sorbent (Phenomenex, Torrance, CA) as described by others (Kaluzny et al., 1985). Briefly, after conditioning of the cartridges with hexane, the NL fraction was eluted with chloroform:2-propanol (2:1), the NEFA fraction with $2 \%$ acetic acid in diethyl ether, and the PL fraction with methanol. 1,2-Diheneicosanoyl-sn-glycero-3-phosphocholine (21:0 PC) was used as internal standard for lipid fractioning. Fatty acids from total extractions and each lipid fraction were transesterified and methylated using 20\% methanolic hydrochloric acid for $2 \mathrm{~h}$ at $90^{\circ} \mathrm{C}$ (Browse et al., 1986). Methylated extractions were analyzed using a Perkin Elmer Clarus 500 gas chromatography apparatus (Perkin Elmer, Waltham, MA) with a Supelco SP-2560 column $(100 \mathrm{~m} \times 25 \mathrm{~mm}$ with a $0.2-\mu \mathrm{m}$ film thickness; Supelco, Bellefonte, PA). Fatty acid peaks were identified by using a mix of pure methyl ester standards (Nu-Chek Prep, Elysian, MN).

Serum total NEFA concentrations were quantified with the NEFA-HR-2 kit (Wako, Richmond, VA), following the manufacturer's protocol. Nine standards were prepared from the supplied stock (0.1 to $1.3 \mathrm{mEq} / \mathrm{L})$.
Table 2. Fatty acid composition of precalving and lactation diets

\begin{tabular}{lrc}
\hline & \multicolumn{2}{c}{ Diet } \\
\cline { 2 - 3 } Fatty acid, g/d & Transition & Lactation \\
\hline C12:0 & 0.99 & 7.45 \\
C14:0 & 1.24 & 7.72 \\
C16:0 & 41.67 & 113.81 \\
C16:1 & 1.08 & 4.11 \\
C18:0 & 7.34 & 28.92 \\
C18:1 & 40.18 & 141.96 \\
C18:2 & 105.85 & 264.36 \\
C18:3 & 34.00 & 49.78 \\
Other & 7.43 & 20.55 \\
\hline
\end{tabular}

Samples, standards, and blanks were run in triplicate in a 96-well microplate at $6 \mu \mathrm{L}$ per well. The microplate was incubated twice for $5 \mathrm{~min}$ after adding each of the 2 reagents. The samples were read at $550 \mathrm{~nm}$ using a Victor microplate reader (Perkin Elmer).

\section{Statistical Analysis}

Variables were analyzed as repeated measures using a mixed model procedure (PROC MIXED; SAS Inst. Inc., Cary NC). The following model was used to estimate the sampling day effect on each of the measured variables:

$$
\mathrm{Y}_{\mathrm{ij}}=\mu+\mathrm{S}_{\mathrm{i}}+\mathrm{e}_{\mathrm{ij}}
$$

where $Y_{i j}$ is the dependent variable for cow $_{\mathrm{i}}$ in sample $\mathrm{j}_{\mathrm{j}}$ relative to calving; $\mu$ is the overall mean of the population; $\mathrm{S}_{\mathrm{i}}$ is the fixed effect of time as the repeated factor; and $\mathrm{e}_{\mathrm{ij}}$ is the random error, assumed to be correlated. Least squares means were calculated and adjusted using the Tukey-Kramer method. The CORR procedure of SAS was used to determine correlations between specific fatty acid concentrations in different lipid fractions in plasma and PBMC, total plasma NEFA $(\mathrm{mEq} / \mathrm{L})$, and the percentage values for specific PBMC phenotypes. Significance was set at $\alpha=0.05$.

\section{RESULTS}

\section{PBMC Populations}

Changes in leukocyte populations were observed when comparing phenotype distributions at different sampling stages (Figure 1). As described in previous reports (Shafer-Weaver et al., 1999), monocyte/granulocyte populations (CD172a) were highest at calving but decreased significantly at 14 and 30 d of lactation. Similarly, the expression of CD14 (a co-receptor expressed on monocytes) increased significantly at parturition compared with values at other sampling time 


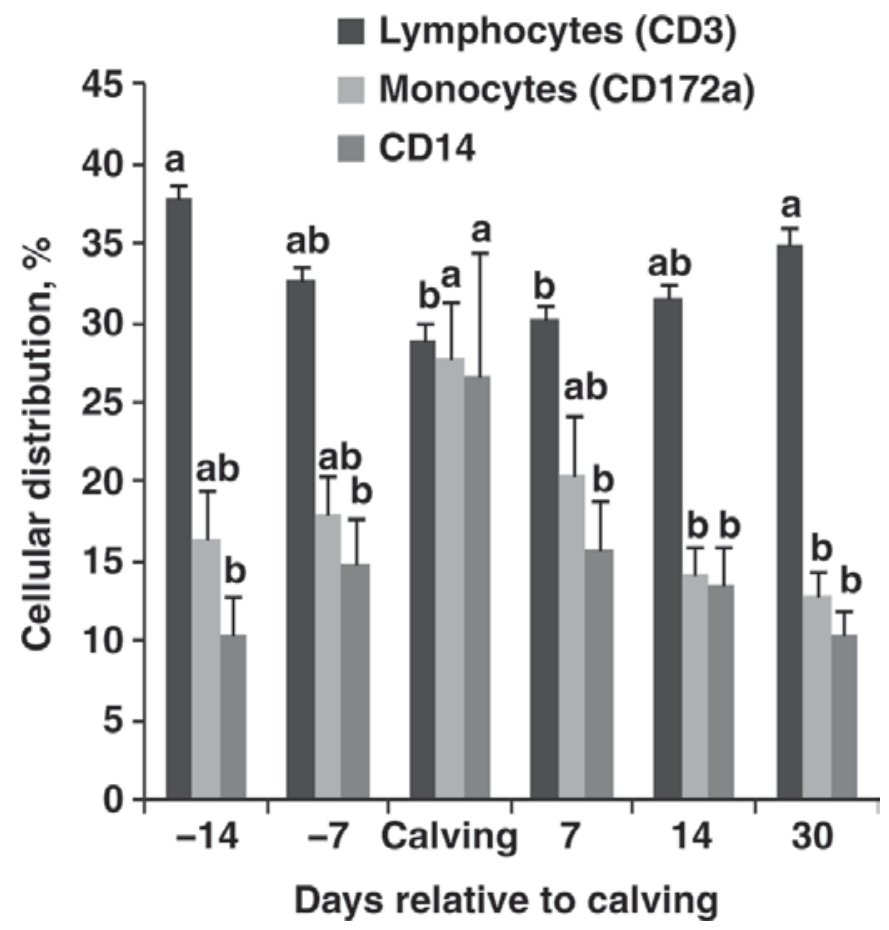

Figure 1. Peripheral blood mononuclear cells (PBMC) phenotype distribution changes relative to calving date in periparturient dairy cows $(n=10)$. Values are percentage of the population \pm SEM as measured by flow cytometry using specific bovine monoclonal antibodies. Phenotypes were characterized by the expression of CD3 for lymphocytes and CD172a for monocytes. CD14 is a co-receptor that also identifies monocytes in the total PBMC population. Means without a common letter differ across the time points, $P<0.05$.

points. In contrast, the T-cell subpopulation (CD3) presented a significant decrease at calving and at $7 \mathrm{~d}$ in milk compared with values at $14 \mathrm{~d}$ before calving and $30 \mathrm{~d}$ in lactation.

\section{Lipid Fractions in Plasma and PBMC}

Concentrations of NEFA are shown in Figure 2. Lipomobilization was demonstrated by a significant increase of plasma NEFA at calving $(0.54 \mathrm{mEq} / \mathrm{L})$ and $7 \mathrm{~d}(0.67$ $\mathrm{mEq} / \mathrm{L})$ compared with prepartum $(-14 \mathrm{~d}$ and $-7 \mathrm{~d})$ and early lactation levels (14 and $30 \mathrm{~d}$ ).

The fatty acid composition of plasma lipids is shown in Table 3. Linoleic acid was the main fatty acid and its weight percentage increased significantly during early lactation (14 d and $30 \mathrm{~d}$ ) compared with values before parturition and during the first week after calving. In contrast, stearic acid values decreased from $14 \mathrm{~d}$ before parturition through early lactation $(30 \mathrm{~d})$, and values at $7 \mathrm{~d}$ before due date $(16.36 \mathrm{~g} / 100 \mathrm{~g})$ were significantly higher than those observed at $30 \mathrm{~d}(12.86 \mathrm{~g} / 100 \mathrm{~g})$. Oleic acid values increased from $7 \mathrm{~d}$ before calving until $14 \mathrm{~d}$ in milk, coinciding with plasma NEFA increment. Oleic acid concentration decreased, however, by 30
DIM. Values for myristic, palmitic, arachidonic, and docosahexaenoic (DHA) acids were constant through the periparturient period. Eicosapentaenoic acid (EPA) concentrations were undetected in the total plasma lipid samples.

The plasma PL fraction composition is presented in Table 4 . The predominant fatty acids in this lipid fraction were palmitic and stearic acids. The concentration of palmitic acid was lower at $14 \mathrm{~d}$ before due date (26.01 $\mathrm{g} / 100 \mathrm{~g}$ ), increasing gradually until reaching its highest point at $14 \mathrm{~d}$ after calving (37.76 g/100 g). Linoleic acid concentration was significantly higher during the first week after calving $(10.67 \mathrm{~g} / 100 \mathrm{~g})$ compared with other time points. Whereas EPA concentrations were significantly higher in early lactation samples compared with precalving samples, arachidonic acid and DHA concentrations were found to be steady throughout the periparturient period.

The plasma NEFA composition is presented in Table 5. As in the PL fraction, palmitic and stearic acids were the predominant fatty acids. Palmitic acid values increased significantly from $14 \mathrm{~d}(25.86 \mathrm{~g} / 100 \mathrm{~g})$ and $7 \mathrm{~d}(25.29 \mathrm{~g} / 100 \mathrm{~g})$ before parturition compared with $7 \mathrm{~d}$ in lactation $(32.81 \mathrm{~g} / 100 \mathrm{~g})$. Oleic, linoleic, and DHA concentrations remained unchanged through the 6-wk follow-up period. Arachidonic acid and EPA were detected in very low concentrations in this fraction.

The fatty acid composition of the PBMC PL fraction is shown in Table 6. Reflecting the profiles of plasma NEFA and PL fractions, the predominant fatty acids were palmitic and stearic. Palmitic acid significantly increased from the week before calving $(-7 \mathrm{~d}, 30.96 \mathrm{~g} / 100$ g) compared with $7 \mathrm{~d}(34.75 \mathrm{~g} / 100 \mathrm{~g}), 14 \mathrm{~d}(35.79 \mathrm{~g} / 100$ $\mathrm{g})$, and $30 \mathrm{~d}(35.04 \mathrm{~g} / 100 \mathrm{~g})$. Myristic and stearic acids remained constant through the sample period. Linoleic acid concentrations increased significantly after parturition. Measures of long-chain polyunsaturated fatty

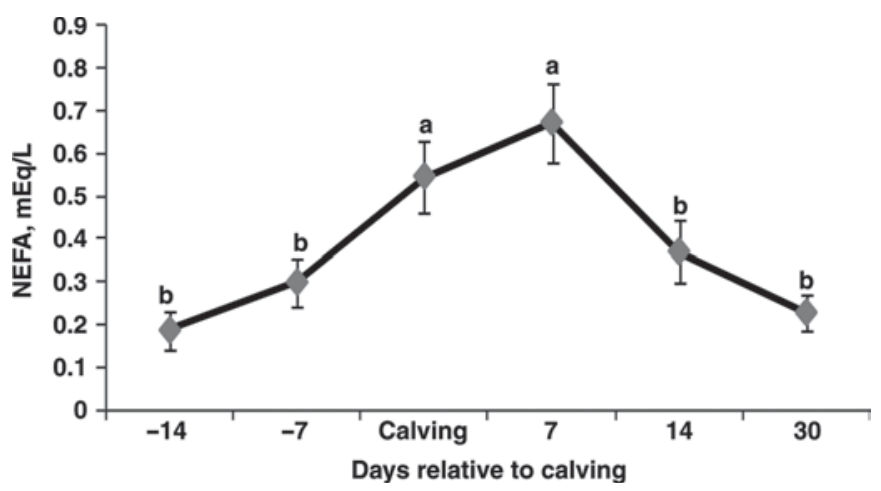

Figure 2. Plasma NEFA concentrations (mEq/L) \pm SEM in dairy cows during the periparturient period $(\mathrm{n}=10)$. Means without common letters differ, $P<0.05$. 
Table 3. Fatty acid composition (mean \pm SEM) of total fatty acids in plasma of dairy cows $(\mathrm{n}=10)$

\begin{tabular}{|c|c|c|c|c|c|c|c|c|}
\hline Day $^{1}$ & \multicolumn{8}{|c|}{ Fatty acid, ${ }^{2} \mathrm{~g} / 100 \mathrm{~g}$} \\
\hline-14 & $0.71 \pm 0.36$ & $14.22 \pm 0.91$ & $18.88 \pm 2.13^{\mathrm{ab}}$ & $11.64 \pm 1.14^{\mathrm{b}}$ & $26.03 \pm 1.84^{\mathrm{b}}$ & $2.97 \pm 0.22$ & - & $1.10 \pm 0.37$ \\
\hline 0 & $1.02 \pm 0.22$ & $15.91 \pm 0.35$ & $15.46 \pm 0.88^{\mathrm{ab}}$ & $14.96 \pm 1.16^{\mathrm{ab}}$ & $28.02 \pm 1.40^{\mathrm{b}}$ & $3.15 \pm 0.12$ & - & $0.67 \pm 0.07$ \\
\hline 7 & $0.79 \pm 0.22$ & $15.47 \pm 0.42$ & $14.69 \pm 0.64^{\mathrm{ab}}$ & $14.99 \pm 0.55^{\mathrm{a}}$ & $32.01 \pm 1.33^{\mathrm{b}}$ & $2.78 \pm 0.16$ & - & $0.77 \pm 0.12$ \\
\hline 14 & $0.52 \pm 0.15$ & $15.18 \pm 0.53$ & $13.33 \pm 0.67^{\mathrm{ab}}$ & $12.81 \pm 0.80^{\mathrm{ab}}$ & $35.79 \pm 1.45^{\mathrm{a}}$ & $2.67 \pm 0.20$ & - & $1.00 \pm 0.24$ \\
\hline
\end{tabular}

a,b Means in a column without a common letter differ, $P<0.05$.

${ }^{1}$ Day relative to parturition.

${ }^{2} \mathrm{C} 14: 0=$ myristic acid, C16:0 = palmitic acid, C18:0 = stearic acid, C18:1 = oleic acid, C18:2 = linoleic acid, C20:4 = arachidonic acid, C20:5 $=$ eicosapentaenoic acid, C22:6 = docosahexaenoic acid.

acids (PUFA), including arachidonic acid, EPA, and DHA, were variable throughout the sampling period.

Correlation coefficients were calculated to establish interactions between plasma NEFA concentration, the most common fatty acids in plasma NEFA and PL (palmitic and stearic acids), and the percentage of monocytes within the PBMC population (Table 7). The concentration of NEFA was positively correlated with concentrations of palmitic acid in PBMC $(\mathrm{r}=$ $0.394)$ and palmitic acid in plasma PL $(\mathrm{r}=0.326)$ and the percentage of monocytes in PBMC $(r=0.424)$. The NEFA value was negatively correlated with values for stearic acid in plasma NEFA $(\mathrm{r}=-0.35)$. The values of stearic acid in the PL fraction of PBMC were correlated with palmitic acid in PL of PBMC and plasma PL ( $\mathrm{r}$ $=0.305)$. Within the plasma NEFA fraction, values for stearic and palmitic acids were highly correlated $(\mathrm{r}=$ $0.825)$.

\section{DISCUSSION}

Common physiological events associated with mammalian parturition and the onset of lactation drive changes in lipolysis and lipogenesis. Lipomobilization is a physiological adaptation by mammals in response to reduced nutrient and energy availability. Previous research showed that lipomobilization not only affects relative concentrations of total plasma lipids and corresponding fractions, but also causes major shifts in fatty acid composition (Douglas et al., 2007). Results from the present study confirmed this observation as total lipid fatty acid profiles varied from prepartum to early lactation sampling periods. Linoleic acid concentrations increased after parturition in contrast to stearic acid values, which decreased as lactation progressed. These modifications in the plasma total lipid fatty acid profile reflected changes in the diet and the increased rate of lipomobilization. However, fatty acid composition of total plasma lipids does not reflect the fatty acid profile of certain plasma lipid fractions. This is due, in part, to differences in fatty acid distributions among lipid classes. For example, linoleic acid is preferentially found in the NL fraction within cholesterol esters, whereas PUFA (arachidonic acid and EPA) are found in the PL fraction. These particularities were demonstrated by others in late (Tyburczy et al., 2008) and early (Leroy et al., 2005) lactation cows.

The fatty acids of the various serum lipid fractions have different metabolic fates and functions. Neutral lipids (triglycerides, diglycerides, monoglycerides, and cholesterol esters) are intermediate molecules of lipid metabolism with dense energy content, but they re-

Table 4. Fatty acid composition (mean \pm SEM) of plasma phospholipid fraction of dairy cows $(\mathrm{n}=10)$

\begin{tabular}{|c|c|c|c|c|c|c|c|c|}
\hline Day $^{1}$ & \multicolumn{8}{|c|}{ Fatty acid, ${ }^{2} \mathrm{~g} / 100 \mathrm{~g}$} \\
\hline-14 & $1.47 \pm 0.07$ & $26.01 \pm 0.90^{\mathrm{b}}$ & $36.74 \pm 2.89$ & $8.37 \pm 1.55$ & $6.14 \pm 1.39^{\mathrm{b}}$ & $1.28 \pm 0.46$ & $1.13 \pm 0.06^{\mathrm{b}}$ & $0.73 \pm 0.34$ \\
\hline 0 & $1.67 \pm 0.11$ & $35.14 \pm 1.86^{\mathrm{ab}}$ & $35.44 \pm 1.60$ & $5.29 \pm 0.81$ & $4.02 \pm 0.91^{\mathrm{b}}$ & $1.06 \pm 0.20$ & $1.63 \pm 0.13^{\mathrm{ab}}$ & $0.69 \pm 0.10$ \\
\hline 7 & $1.22 \pm 0.08$ & $33.46 \pm 2.38^{\mathrm{ab}}$ & $32.71 \pm 2.35$ & $7.72 \pm 1.36$ & $10.67 \pm 1.24^{\mathrm{a}}$ & $1.24 \pm 0.19$ & $1.45 \pm 0.17^{\mathrm{ab}}$ & $0.59 \pm 0.05$ \\
\hline 14 & $1.39 \pm 0.12$ & $37.76 \pm 1.80^{\mathrm{a}}$ & $34.77 \pm 1.52$ & $4.05 \pm 0.58$ & $4.47 \pm 1.19^{\mathrm{b}}$ & $0.58 \pm 0.13$ & $1.73 \pm 0.08^{\mathrm{a}}$ & $1.10 \pm 0.17$ \\
\hline
\end{tabular}

${ }^{\mathrm{a}, \mathrm{b}}$ Means in a column without a common letter differ, $P<0.05$.

${ }^{1}$ Day relative to parturition.

${ }^{2} \mathrm{C} 14: 0=$ myristic acid, C16:0 = palmitic acid, C18:0 = stearic acid, C18:1 = oleic acid, C18:2 = linoleic acid, C20:4 = arachidonic acid, C20:5 $=$ eicosapentaenoic acid, C22:6 = docosahexaenoic acid. 
Table 5. Fatty acid composition (mean \pm SEM) of plasma NEFA fraction of dairy cows $(\mathrm{n}=10)$

\begin{tabular}{|c|c|c|c|c|c|c|c|c|}
\hline Day $^{1}$ & \multicolumn{8}{|c|}{ Fatty acid, ${ }^{2} \mathrm{~g} / 100 \mathrm{~g}$} \\
\hline-14 & $2.50 \pm 0.22$ & $25.86 \pm 0.76^{\mathrm{b}}$ & $40.46 \pm 0.57$ & $10.20 \pm 3.02$ & $0.89 \pm 0.27$ & - & - & $0.72 \pm 0.11$ \\
\hline 0 & $2.17 \pm 0.12$ & $27.20 \pm 1.21^{\mathrm{ab}}$ & $35.75 \pm 2.35$ & $13.51 \pm 3.54$ & $1.07 \pm 0.19$ & - & $0.74 \pm 0.05$ & $1.96 \pm 0.42$ \\
\hline 7 & $2.04 \pm 0.35$ & $32.81 \pm 1.59^{\mathrm{a}}$ & $43.52 \pm 2.74$ & $3.19 \pm 2.24$ & $0.68 \pm 0.28$ & - & $0.26 \pm 0.26$ & $2.48 \pm 0.56$ \\
\hline 14 & $2.15 \pm 0.30$ & $27.77 \pm 1.56^{\mathrm{ab}}$ & $39.48 \pm 2.48$ & $6.57 \pm 2.10$ & $1.28 \pm 0.55$ & - & $0.78 \pm 0.04$ & $2.08 \pm 0.44$ \\
\hline
\end{tabular}

${ }_{\mathrm{a}, \mathrm{b}}$ Means in a column without a common letter differ, $P<0.05$.

${ }^{1}$ Day relative to parturition.

${ }^{2} \mathrm{C} 14: 0=$ myristic acid, C16:0 = palmitic acid, C18:0 = stearic acid, C18:1 = oleic acid, C18:2 = linoleic acid, C20:4 = arachidonic acid, C20:5 $=$ eicosapentaenoic acid, C22:6 = docosahexaenoic acid.

quire the activity of lipoprotein lipases to provide such energy to different tissues. Phospholipids, on the other hand, are the main components of biological membranes, including the unilamellar membrane of serum lipoproteins. Phospholipids provide lipid substrates for the biosynthesis of potent proinflammatory mediators, including the eicosanoids and platelet-activating factor (Henneberry et al., 2002). Finally, NEFA are involved in intracellular signaling processes, modification of cellular functions, and as energy substrates.

In general, reduction in the body content of adipose tissue (lipomobilization), as reflected by an increase in NEFA, leads to impaired metabolic and immune cell functions (Mora and Pessing, 2002). In humans, increased NEFA concentrations were linked to inflammatory-based diseases such as asthma, atherosclerosis, metabolic syndrome, and type 2 diabetes (Boden, 2008; Wood et al., 2009). Previous studies in dairy cows also demonstrated that elevated NEFA during the periparturient period largely affect immune cell functions (Lacetera et al., 2004; Scalia et al., 2006). In the present study, plasma NEFA concentrations were correlated positively with changes in PBMC populations, particularly with the relative percentage of monocytes in circulation. The activity of this subset of mononuclear cells is especially modified during the periparturient period, exhibiting enhanced production of proinflammatory cytokines (Sordillo et al., 1995). A recent report in humans demonstrated that increased cytokine production by macrophages is influenced greatly by palmitic and stearic FA (Håversen et al., 2009). Therefore, immune cell activity during the periparturient period may be affected not only by the quantity of NEFA in blood, but also by the profile of its fatty acids.

A known consequence of increased concentrations of NEFA in plasma is the alteration of the physiological functions of their main transporter, albumin. In periparturient dairy cows, plasma concentrations of this protein are known to be diminished especially during the first weeks after parturition (Trevisi et al., 2009). Albumin is considered a negative acute phase protein, implying that its blood concentration decreases during systemic inflammation (Murata et al., 2004). Reduced concentrations of albumin during the periparturient period accompanied by intense lipomobilization rapidly increase the NEFA to albumin ratio. In humans, the consequences of an elevated NEFA to albumin ratio predispose subjects to immune-endothelial dysfunction diseases such as pre-eclampsia (Endresen et al., 1992) and to metabolic diseases such as type 2 diabetes

Table 6. Fatty acid composition (mean \pm SEM) of peripheral blood mononuclear cells phospholipid fraction of dairy cows $(\mathrm{n}=10)$

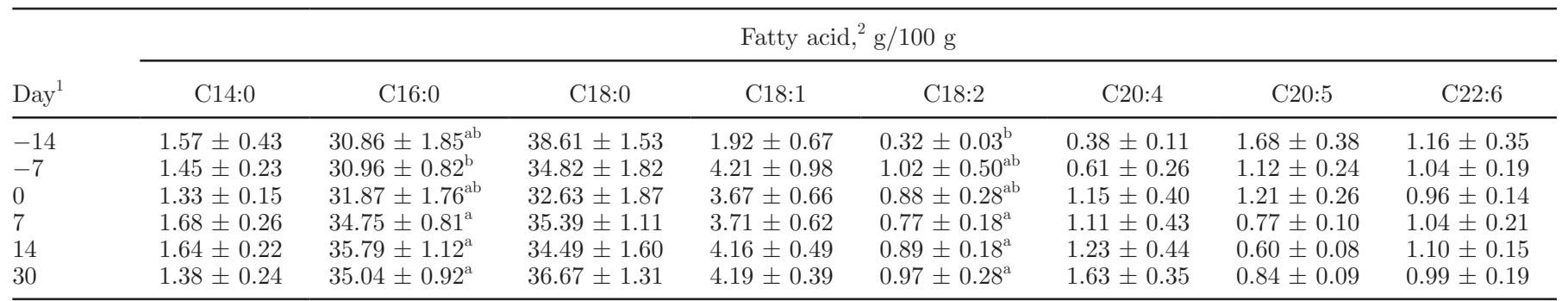

a,b Means in a column without a common letter differ, $P<0.05$.

${ }^{1}$ Day relative to parturition.

${ }^{2} \mathrm{C} 14: 0=$ myristic acid, C16:0 = palmitic acid, C18:0 = stearic acid, C18:1 = oleic acid, C18:2 = linoleic acid, C20:4 = arachidonic acid, C20:5 $=$ eicosapentaenoic acid, C22:6 = docosahexaenoic acid. 
Table 7. Pearson correlation coefficients for NEFA, selected fatty acids in different plasma lipid fractions, and mononuclear cell values of periparturient dairy $\operatorname{cows}^{1}(\mathrm{n}=10)$

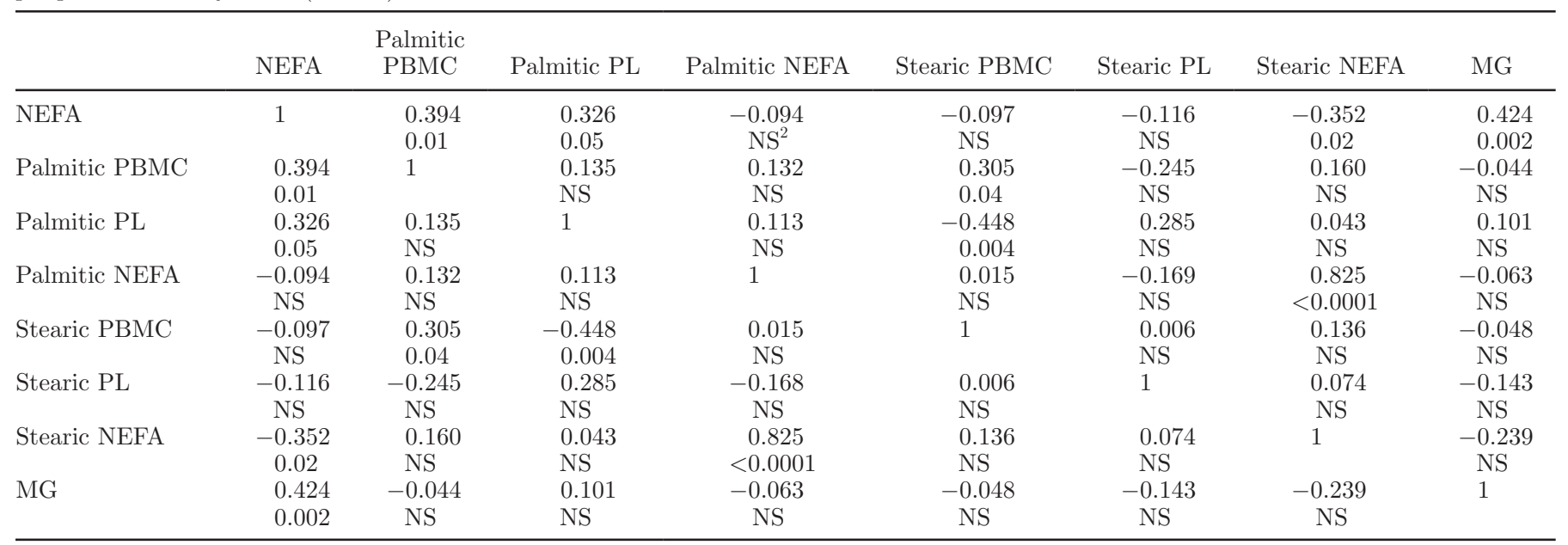

${ }^{1} \mathrm{PBMC}=$ peripheral blood mononuclear cells; $\mathrm{PL}=$ phospholipids; $\mathrm{MG}=$ percentage of mononuclear cell population reactive to monocyte/ granulocyte antibody (CD172).

${ }^{2} P>0.05$.

(Cnop et al., 2001). The physiological consequences of altered NEFA to albumin ratio in the dairy cow warrant further investigation.

In contrast to total lipid fatty acid profile in plasma where linoleic acid was the main fatty acid, the principal components of plasma NEFA and PL were palmitic, stearic, and oleic acids. During lipomobilization events, hormone-sensitive lipases and triglyceride lipase release fatty acids from triglyceride depots in the adipose tissue (Kershaw et al., 2006). These molecules are released into the circulation and transported bound to albumin. A logical conclusion is that during periods of negative energy balance, NEFA profiles may directly reflect the fatty acid composition of adipose tissue. In fact, a recent study described the fatty acid profiles of subcutaneous adipose tissue in periparturient cows and found that the main fatty acids were palmitic, stearic, and oleic acids (Douglas et al., 2007). Although our study did not evaluate fatty acid profiles in adipose tissue, differences between plasma NEFA and adipose tissue composition should be expected. In human adipose tissue, for example, long-chain unsaturated fatty acids are preferentially mobilized from and re-extracted by adipose tissue during lipolysis and lipogenesis (Raclot, 2003), respectively. In dairy cattle, the patterns of fatty acid trafficking from adipose tissue during lipomobilization are unknown. Another potential explanation for differences between adipose tissue and plasma NEFA profiles is that the fatty acid composition of adipose tissue varies depending on anatomical localization (e.g., visceral vs. subcutaneous depots). Therefore, the composition of lipid deposits that poses higher mass and blood irrigation has higher influence on the final NEFA profile during lipomobilization events. Indeed, human visceral fat is higher in saturated fatty acids including palmitic and stearic acids compared with subcutaneous fat (Phinney et al., 1994). Further studies are required to improve our knowledge with respect to lipomobilization, including the effect of adipose tissue site, fatty acid composition of adipose deposits, and the preferential mobilization of specific fatty acids in periparturient dairy cows. Despite the importance of plasma NEFA composition on the inflammatory process, there is a lack of knowledge about variations in plasma NEFA profiles during different production stages in dairy cows. Indeed, the majority of studies in periparturient cows that include dietary or pharmacological interventions to improve periparturient dairy cows' health only describe the total fatty acid concentration.

The NEFA profile composition was reflective of the fatty acid contents of plasma and PBMC PL fractions. Various research groups demonstrated in humans that the lipid composition of the PL fraction of immune cells directly affects their physiological function and response to inflammatory stimuli (Kew et al., 2003; Trebble et al., 2004). The saturated palmitic and stearic fatty acid components of this fraction increased during weeks of intense lipomobilization. Both of these saturated fatty acids are known for their proinflammatory characteristics, including the ability to activate different intracellular inflammatory signaling pathways including nuclear factor- $\kappa \mathrm{B}$ and mitogen-activated protein kinase (MAPK; Calder and Yaqoob, 2007; Serhan et al., 2008). Palmitic and stearic acids can also promote inflammation by enhancing the production of inflammatory cytokines and lipid mediators. For example, palmitic acid 
through its activated molecule palmitoyl-coA is able to enhance the production of the cytokines tumor necrosis factor- $\alpha$, IL-1 $\beta$, and IL- 8 in monocytes. Additionally, stearate and palmitate can induce the expression of cyclooxygenase 2, an inflammatory eicosanoid enzyme (Lee et al., 2001), via activating toll-like receptor-4. Several recent studies reported increased expression of several proinflammatory genes in periparturient cows (Loor et al., 2005; Sordillo, 2005; Aitken et al., 2009). Although conjecture, the increased concentrations of saturated fatty acids in the different plasma and cellular lipid fractions may contribute to increased inflammatory responses of periparturient dairy cows.

In contrast to saturated fatty acids, the concentrations of PUFA in plasma NEFA and PL as well as in the PL fraction of PBMC were low compared with values reported in other species (Kew et al., 2003; Fritsche, 2007). Ruminants have limited availability of PUFA because of biohydrogenation of these compounds in the rumen and the limited synthesis of such acids by ruminal bacteria (Jenkins, 1993). Dairy cows have partially offset this limited availability by their very efficient intestinal fatty acid absorption of PUFA (Bauchart, 1993). Reduced levels of PUFA are detrimental to immune cell function (Harbige, 2003). These fatty acids are the substrate for the synthesis of several lipid mediators. Depending on the fatty acid used as substrate and the biosynthetic enzyme, these molecules act as initiators, modulators, or resolvers of inflammation (Serhan et al., 2008). Previous studies in humans have demonstrated that PUFA supplementation, specifically n-3 fatty acids, improves the outcome of inflammatory diseases such as rheumatoid arthritis, asthma, and atherosclerosis (Kris-Etherton et al., 2003; Wong, 2005; Galarraga et al., 2008). In dairy cows, various research groups have evaluated effects of PUFA supplementation on immune cell function during the periparturient period (Lessard et al., 2003, 2004; Rodriguez-Sallaberry et al., 2007). None of these studies, however, evaluated the effectiveness of PUFA supplementation to change the fatty acid composition of immune cells, although it has been proven to change the lipid profile of liver and adipose tissue (Douglas et al., 2007). This study elucidated the implications of lipomobilization during the periparturient period on fatty acid composition of plasma lipid fractions and PL of immune cells. Based on our findings and observations in human medicine, future evaluations of fatty acid supplementation in periparturient dairy cows should include a critical evaluation of the shifts in these fractions.

\section{CONCLUSIONS}

Lipomobilization is a common physiological process during the periparturient period of mammalian species, and it functions to provide energy to the dam during periods of increased energy requirements due to fetal growth and lactogenesis. However, this process is exacerbated in dairy cows because of their homeorhetic drive to meet genetic potential for milk production. Although lipomobilization increases energy availability, it also affects lipid homeostasis and promotes changes in the fatty acid profiles of different plasma lipid fractions. In the present study, palmitic and stearic acids were the most prominent components of plasma NEFA and PL. The composition of both plasma lipid fractions was reflected in the fatty acid profile of the PL fraction of PBMC. Increased concentrations of saturated fatty acids and diminished amounts of PUFA in the PL fraction of PBMC could negatively affect the immune cell response during the periparturient period. Further studies are needed to better characterize lipomobilization during the periparturient period and its consequences on lipid homeostasis, metabolism, and immune cell function.

\section{ACKNOWLEDGMENTS}

Authors acknowledge the technical assistance of Justin Zyskowski (Diagnostic Center for Population and Animal Health, Lansing, MI) for laboratory analyses. This project was supported in part by National Research Initiative Grants 2005-35204-16001 and 200735204-18463 from the USDA National Institute for Food and Agriculture and by an endowment from the Matilda R. Wilson Fund (Detroit, MI).

\section{REFERENCES}

Adewuyi, A. A., E. Gruys, and F. van Eerdenburg. 2005. Non esterified fatty acids (NEFA) in dairy cattle. A review. Vet. Q. 27:117126.

Aitken, S. L., E. L. Karcher, P. Rezamand, J. C. Gandy, M. J. VandeHaar, A. V. Capuco, and L. M. Sordillo. 2009. Evaluation of antioxidant and proinflammatory gene expression in bovine mammary tissue during the periparturient period. J. Dairy Sci. 92:589-598.

Al, M. D. M., A. C. Van Houwelingen, A. D. M. Kester, T. H. M. Hasaart, A. E. P. De Jong, and G. Hornstra. 1995. Maternal essential fatty acid patterns during normal pregnancy and their relationship to the neonatal essential fatty acid status. Br. J. Nutr. 74:55-68.

Bauchart, D. 1993. Lipid absorption and transport in ruminants. J. Dairy Sci. 76:3864-3881.

Boden, G. 2008. Obesity and free fatty acids. Endocrinol. Metab. Clin. North Am. 37:635-646.

Browse, J., P. J. McCourt, and C. R. Somerville. 1986. Fatty acid composition of leaf lipids determined after combined digestion and fatty acid methyl ester formation from fresh tissue. Anal. Biochem. 152:141-145.

Calder, P. C., and P. Yaqoob. 2007. Lipid rafts-Composition, characterization, and controversies. J. Nutr. 137:545-547.

Cnop, M., J. C. Hannaert, A. Hoorens, D. L. Eizirik, and D. G. Pipeleers. 2001. Inverse relationship between cytotoxicity of free fatty acids in pancreatic islet cells and cellular triglyceride accumulation. Diabetes 50:1771-1777. 
Douglas, G. N., J. Rehage, A. D. Beaulieu, A. O. Bahaa, and J. K. Drackley. 2007. Prepartum nutrition alters fatty acid composition in plasma, adipose tissue, and liver lipids of periparturient dairy cows. J. Dairy Sci. 90:2941-2959.

Drackley, J. K. 1999. Biology of dairy cows during the transition period: The final frontier? J. Dairy Sci. 82:2259-2273.

Endresen, M. J., B. Lorentzen, and T. Henriksen. 1992. Increased lipolytic activity and high ratio of free fatty acids to albumin in sera from women with preeclampsia leads to triglyceride accumulation in cultured endothelial cells. Am. J. Obstet. Gynecol. 167:440447.

Fritsche, K. 2007. Important differences exist in the dose-response relationship between diet and immune cell fatty acids in humans and rodents. Lipids 42:961-979.

Galarraga, B., M. Ho, H. M. Youssef, A. Hill, H. McMahon, C. Hall, S. Ogston, G. Nuki, and J. J. F. Belch. 2008. Cod liver oil (n-3 fatty acids) as an non-steroidal anti-inflammatory drug sparing agent in rheumatoid arthritis. Rheumatology 47:665-669.

Grummer, R. R. 1993. Etiology of lipid-related metabolic disorders in periparturient dairy cows. J. Dairy Sci. 76:3882-3896.

Hanebutt, F. L., H. Demmelmair, B. Schiessl, E. Larqué, and B. Koletzko. 2008. Long-chain polyunsaturated fatty acid (LC-PUFA) transfer across the placenta. Clin. Nutr. 27:685-693.

Harbige, L. S. 2003. Fatty acids, the immune response, and autoimmunity: A question of $\mathrm{n}-6$ essentiality and the balance between n-6 and n-3. Lipids 38:323-341.

Håversen, L., K. N. Danielsson, L. Fogelstrand, and O. Wiklund. 2009 Induction of proinflammatory cytokines by long-chain saturated fatty acids in human macrophages. Atherosclerosis 202:382-393.

Henneberry, A. L., M. M. Wright, and C. R. McMaster. 2002. The major sites of cellular phospholipid synthesis and molecular determinants of fatty acid and lipid head group specificity. Mol. Biol. Cell 13:3148-3161.

Hocquette, J. F., and D. Bauchart. 1999. Intestinal absorption, blood transport and hepatic and muscle metabolism of fatty acids in preruminant and ruminant animals. Reprod. Nutr. Dev. 39:2748.

Jenkins, T. C. 1993. Lipid metabolism in the rumen. J. Dairy Sci. $76: 3851-3863$

Kaluzny, M. A., L. A. Duncan, M. V. Merritt, and D. E. Epps. 1985. Rapid separation of lipid classes in high yield and purity using bonded phase columns. J. Lipid Res. 26:135-140.

Kershaw, E. E., J. K. Hamm, L. A. W. Verhagen, O. Peroni, M Katic, and J. S. Flier. 2006. Adipose triglyceride lipase. Diabetes $55: 148-157$.

Kew, S., T. Banerjee, A. M. Minihane, Y. E. Finnegan, C. M. Williams, and P. C. Calder. 2003. Relation between the fatty acid composition of peripheral blood mononuclear cells and measures of immune cell function in healthy, free-living subjects aged 25-72 y. Am. J. Clin. Nutr. 77:1278-1286.

Kris-Etherton, P. M., W. S. Harris, and L. J. Appel., and Nutrition Committee. 2003. Fish consumption, fish oil, omega-3 fatty acids, and cardiovascular disease. Arterioscler. Thromb. Vasc. Biol. 23:e20-e30.

Lacetera, N., D. Scalia, O. Franci, U. Bernabucci, B. Ronchi, and A. Nardone. 2004. Short communication: Effects of nonesterified fatty acids on lymphocyte function in dairy heifers. J. Dairy Sci. 87:1012-1014.

Lee, J. Y., K. H. Sohn, S. H. Rhee, and D. Hwang. 2001. Saturated fatty acids, but not unsaturated fatty acids, induce the expression of cyclooxygenase- 2 mediated through toll-like receptor 4 . J. Biol. Chem. 276:16683-16689.

Leroy, J. L. M. R., T. Vanholder, B. Mateusen, A. Christophe, G Opsomer, A. de Kruif, G. Genicot, and A. Van Soom. 2005. Nonesterified fatty acids in follicular fluid of dairy cows and their effect on developmental capacity of bovine oocytes in vitro. Reproduction 130:485-495.

Lessard, M., N. Gagnon, D. L. Godson, and H. V. Petit. 2004. Influence of parturition and diets enriched in n-3 or n-6 polyunsaturated fatty acids on immune response of dairy cows during the transition period. J. Dairy Sci. 87:2197-2210.

Lessard, M., N. Gagnon, and H. V. Petit. 2003. Immune response of postpartum dairy cows fed flaxseed. J. Dairy Sci. 86:2647-2657.

Loor, J. J., H. M. Dann, R. E. Everts, R. Oliveira, C. A. Green, N. A. J. Guretzky, S. L. Rodriguez-Zas, H. A. Lewin, and J. K. Drackley. 2005. Temporal gene expression profiling of liver from periparturient dairy cows reveals complex adaptive mechanisms in hepatic function. Physiol. Genomics 23:217-226.

Montecucco, F., and F. Mach. 2009. Common inflammatory mediators orchestrate pathophysiological processes in rheumatoid arthritis and atherosclerosis. Rheumatology 48:11-22.

Mora, S., and J. Pessing. 2002. An adipocentric view of signaling and intracellular trafficking. Diabetes Metab. Res. Rev. 18:345-356.

Murata, H., N. Shimada, and M. Yoshioka. 2004. Current research on acute phase proteins in veterinary diagnosis: An overview. Vet. J. 168:28-40

Otto, S. J., A. C. van Houwelingen, A. Badart-Smook, and G. Hornstra. 2001. Comparison of the peripartum and postpartum phospholipid polyunsaturated fatty acid profiles of lactating and nonlactating women. Am. J. Clin. Nutr. 73:1074-1079.

Phinney, S. D., J. S. Stern, K. E. Burke, A. B. Tang, G. Miller, and R. T. Holman. 1994. Human subcutaneous adipose tissue shows site-specific differences in fatty acid composition. Am. J. Clin. Nutr. 60:725-729

Raclot, T. 2003. Selective mobilization of fatty acids from adipose tissue triacylglycerols. Prog. Lipid Res. 42:257-288.

Richieri, G. V., and A. M. Kleinfeld. 1995. Unbound free fatty acid levels in human serum. J. Lipid Res. 36:229-240.

Rodriguez-Sallaberry, C., C. Caldari-Torres, W. Collante, C. R. Staples, and L. Badinga. 2007. Plasma prostaglandin and cytokine concentrations in periparturient Holstein cows fed diets enriched in saturated or trans fatty acids. J. Dairy Sci. 90:5446-5452.

Scalia, D., N. Lacetera, U. Bernabucci, K. Demeyere, L. Duchateau, and C. Burvenich. 2006. In vitro effects of nonesterified fatty acids on bovine neutrophils oxidative burst and viability. J. Dairy Sci. $89: 147-154$

Serhan, C. N., N. Chiang, and T. E. Van Dyke. 2008. Resolving inflammation: Dual anti-inflammatory and pro-resolution lipid mediators. Nat. Rev. Immunol. 8:349-361.

Shafer-Weaver, K. A., C. M. Corl, and L. M. Sordillo. 1999. Shifts in bovine CD4+ subpopulations increase T-helper-2 compared with T-helper-1 effector cells during the postpartum period. J. Dairy Sci. 82:1696-1706.

Sordillo, L. M. 2005. Factors affecting mammary gland immunity and mastitis susceptibility. Livest. Prod. Sci. 98:89-99.

Sordillo, L. M., G. M. Pighetti, and M. R. Davis. 1995. Enhanced production of bovine tumor necrosis factor-[alpha] during the periparturient period. Vet. Immunol. Immunopathol. 49:263270.

Tall, A. 1995. Plasma lipid transfer proteins. Annu. Rev. Biochem. $64: 235-257$.

Trebble, T. M., N. K. Arden, S. A. Wootton, M. A. Mullee, P. C. Calder, G. C. Burdge, D. R. Fine, and M. A. Stroud. 2004. Peripheral blood mononuclear cell fatty acid composition and inflammatory mediator production in adult Crohn's disease. Clin. Nutr. 23:647-655

Trevisi, E., M. Amadori, A. M. Bakudila, and G. Bertoni. 2009 Metabolic changes in dairy cows induced by oral, low-dose interferon-alpha treatment. J. Anim. Sci. 87:3020-3029.

Tyburczy, C., A. L. Lock, D. A. Dwyer, F. Destaillats, Z. Mouloungui, L. Candy, and D. E. Bauman. 2008. Uptake and utilization of trans octadecenoic acids in lactating dairy cows. J. Dairy Sci. 91:3850-3861.

Wong, K. W. 2005. Clinical efficacy of n-3 fatty acid supplementation in patients with asthma. J. Am. Diet. Assoc. 105:98-105.

Wood, L. G., H. A. Scott, M. L. Garg, and P. G. Gibson. 2009 Innate immune mechanisms linking non-esterified fatty acids and respiratory disease. Prog. Lipid Res. 48:27-43. 